\title{
Forming Memory Through Architectural Drawings
}

\author{
Mimari Çizimler ile Bellek Oluşturma
}

\author{
Gaye BEZiRcioĞLU SENVENLi, (D) Gülçin PULAT GÖKMEN
}

Drawing refers to a cognitive activity in which understanding, expressing, experiencing and storing information is performed simultaneously. This article argues that drawing reveals an external and embodied memory while processing information about the environment in which the individual is experienced or constructed. Memory formed by drawing is defined as a memory transferred to the material that has the processing abilities of mental memory such as retention, reactivation and reconstruction of the information. The cognitive process revealed by the drawing includes both the action and the material drawn. In the research, this reflective process is covered through the "distributed cognition" approach which argues that cognition is not limited to the mind but occurs inside the relationship with its environment. With this approach, the present article focuses on the relationship between the drawn and mental representations while investigating the process of recognition and recollection in drawing. The research aims to experience memory formation through drawing in line with the theoretical approach presented. In this context, it questions how the memory that is actively revealed in the drawing process is formed by means of a case study. In the case study, memory traces formed in the drawings as a result of a defined series of drawing activities were observed, and how the spatial experience was represented on the material was analysed. As a result of the study, how the perception of the space is formed and how it is transferred to the material is evaluated in line with the presented theoretical approach.

Keywords: Distributed cognition; drawing; drawn memory; forming memory; traces of the experience.

Çizim bilgiyi anlama, ifade etme, deneyimleme ve depolamanın birlikte ortaya konduğu bilişsel bir aktivitedir. Bu makale, çizimin bireyin deneyimlediği veya inşa ettiği ortam ile ilgili bilgileri işlerken, bu bilginin harici ve somutlaştırılmış bir belleği ortaya koyduğunu savunmaktadır. Çizim yolu ile oluşturulan bellek; bilgiyi tutma, yeniden etkinleştirme, yeniden yapılandırma gibi zihinsel belleğin işlem yetilerine sahip, materyale aktarılmış bir bellek olarak tanımlanmaktadır. Çizimin ortaya koyduğu bilişsel süreç çizim eylemi ve çizilen materyali kapsamaktadır. Araştırmada etkileşimli bu süreç bilişin zihin ile sınırlı kalmadığını, çevre ile kurduğu ilişkide oluştuğunu savunan "dağıtılmış biliş" yaklaşımı üzerinden ele alınmaktadır. Bu yaklaşım ile çizilen temsiller ve zihinsel temsiller arasındaki ilişkiye odaklanılmakta, çizimde tanıma ve anlama süreçleri araştırılmaktadır. Araştırma, çizim yolu ile bellek oluşumunu sunulan teorik yaklaşım doğrultusunda deneyimlemeyi amaçlamaktadır. Bu bağlamda yapılan olgu çalışması aracılığı ile çizim sürecinde aktif olarak ortaya konan belleğin nasıl oluştuğunu sorgulamaktadır. Olgu çalışmasında, tanımlanan bir dizi çizim aktivitesi sonucu çizimlerde oluşan bellek izleri gözlemlenmiş, mekânsal deneyimin materyal üzerinde nasıl temsil edildiği analiz edilmiştir. Çalışmanın sonucunda mekân algısının nasıl oluştuğu ve bunun materyale nasıl aktarıldığı sunulan teorik yaklaşım doğrultusunda değerlendirilmiştir.

Anahtar sözcükler: Dağıtılmış biliş; çizim; çizilmiş hafiza; hafiza oluşturmak; deneyimin izleri.

Department of Architecture, İstanbul Technical University Faculty of Architecture, İstanbul, Turkey 


\section{Introduction}

Drawing, both as a tool and as a method, is used for different purposes in many areas. Besides the representative tool of the materials, drawing is for visual thinking that provides a platform for picturing the mental processes. In these processes, drawing contains data that can be used for the following and also creates relations actively by following each step of the drawing steps. It will be appropriate to define the terms "drawing" and "memory" initially as they are covered in the research.

Drawing is a form of existence. It does not entirely create the physical space but creates an experience of space. In other words, the mere act of drawing is an experiential phenomenon. The thinking and evaluation process extends to the materials and the actions of drawing. It creates perception and a process of thinking that is shaped accordingly. Sketches, or 'Pensieri', which means 'thoughts' in Italian, express the most basic technique in which ideas are put forward. In that sense, sketches have become the focal point of design research. Drawing has also become a method that allows the cognitive process to be presented and read in these studies on design activities. This approach has made the act of drawing itself a subject that needs to be explored. Literature involves studies on the drawing that refers to different cognitive theories. Even though the cognitive process through drawing is modelled or named differently based on different approaches, the consensus between them is the loop between the internal and external cognitive processes. The cognition extends to material and the action of drawing. With this approach, not only the drawn material but also the action of drawing becomes part of the cognitive process and forms an externalised memory.

The term memory has a wide range of definitions based on the context in which it is used. With the most common definition, it is a faculty of mind that stores, organises and reuses the data. The studies on memory go back to the field of philosophy; and over time it has been studied in the branches of perception psychology and neurological sciences. Following these studies, there have been different models to explain the process of coding the perceived data, stages of data storage, and the recall process both from the biological process of the neural system and the cognitive formation aspects. Even though different theories have been built up over time, the basic model of data storage has three stages based on the duration and progress. The first encounter with information, which is called the sensory processor, is sensed in the form of chemical and physical stimuli and processed in the neuron system. The stimuli are encoded and retrieved by the working memory. The stored data covers place in the long-term memory with various categorical models. For the content of this research, the term memory reflects the retention, reactivation, and reconstruction of the experience of drawing.

The article at hand explores the cognitive process during the act of drawing by examining the drawn images. It aims to visualise this relation through the traces of experience on the material that also represents the distributed process of cognition.

\section{Association of the Drawing to Existing Cognitive Theories}

With the studies conducted in cognitive science in the last 20 years, changes in perception have carried the drawing to fields of cognitive studies. Contemporary interdisciplinary methodologies, including practice-based approaches in many disciplines, have begun to research the position of drawing, and in doing so, raising new questions about the role of visualisation and creative thinking in scientific research. Cognitive studies working on the process of cognition examine drawing as a resource that can generate new ideas by thinking.

This approach enables us to study cognitive theories about drawing through practice. With a similar approach, the 12345 Draw group, including Brew, Fava, Kantrowitz, Sheehan, and Fält, focused on studies to explore this relationship. The studies they combined under the name of 'Thinking Through Drawing' aimed to combine cognitive theories with drawing practice. Brew, Fava \& Kantrowitz (2012) describe drawing as 'visible traces of cognitive processes'. In this view, drawing illustrates how experiences are perceived, understood and processed not only within our brains but also with our hands and bodies. Drawing allows the mind to be manipulated with thoughts outside its limits. The group consider drawing as an alternative learning method. The act of making a drawing activates multiple capacities. Therefore, drawing is a unifying action. Lines and signs can be used for new ideas and representations that can be reviewed, expanded and viewed later (Tversky 2002; Kantrowitz et al., 2017).

Different cognitive theories support studies of the 'Thinking Through Drawing' on drawing practices. One of them, the grounded cognition theory, rejects traditional views that differ from the modal (formal) systems of the brain for knowledge, perception, action, and internal observation in the semantic memory system. 'Nervous body in the mind' reconstructs tactile, spatial, and visual experiences to make sense of more abstract ideas (Brew et al., 2012). However, this approach is not sufficient to comprehend the physical activity of drawing and cognitive activities in the drawing process. Another theory that the group emphasises is embodied cognition. This view can be understood as a cognitive process that not only belongs 
to the brain but is also related to the hands and body as the visible trace of the shapes. This awareness allows us to adopt and follow the process of drawing in which the traces of action and movement are completed. Another case the group are investigating is the positioning of the body. Situated cognition argues that knowledge comes from context-dependent activity (Brew et al., 2012).

Following the same concept, Masaki Suwa and Barbara Tversky studied how cognitive processes interact through drawing. They evaluated the drawing process by making a protocol analysis with architects and students. In their studies, sketches and other external representations served as a cognitive tool for expanding memory and thinking. Suwa and Tversky (1997) describe the sketches as a two-stage process. First, it is an external tool to check the consistency and appearance of ideas; second, it generates new ideas and comments. The action of drawing, or the state of actually doing it, sets out a situation that gives direction itself. In other words, drawing has the potential to self-generate through the action. From a similar view, Donald Schön and Glenn Wiggins (1992) define the drawing process in which design thoughts are put forward as a reflective conversation, which is expressed as seeingmoving-seeing. Schön explains the drawing as a reflective practice in which action and product shape each other.

Dialogue and cognitive operations in the design process are examined in more detail in Gabriela Goldschmidt's work. Goldschmidt treats drawing as a kind of thinking. In her studies, she tries to define the psychological activities within the design process and understand the relationship between long-term memory, thinking, description, drawing, and interpretation. According to Goldschmidt (1991), the sketch reflects the logical reasoning process. Design is examined as a way to develop an approach to ill-defined problems as sketches. Her protocol studies focus on the role of modelling and sketching in the design process.

Goldschmidt described the manoeuvres in the design process as an interactive visualisation process in terms of movement and argument. In Goldschmidt's definition, liveaction, that is, the presentation of visual representations and passive action, or thinking, differ from each other. The argument consists of expressions about a particular design movement and its design aspects. The arguments describe the dialectical process between formal features defined as 'seeing as' and non-formal explanations defined as 'seeing that'. There is a circular feedback loop between the internal representation in the image and the external representation on paper. Mental images inform the construction of a draft; however, the draft in the process contains 'autonomous' characteristics, some of which arise from relationships between elements that may be unintentional (Goldschmidt, 1994). Drawing takes place in a way that the mind continues to act and directs the action through a particular compromise. The standard orientation of these two studies is that drawing is an active production of visual thinking.

\section{Evaluation of Drawing via Distributed Cognition}

The 'mind' includes design thinking, design problems, learned information, coding that matches information, shapes, and symbols (specific forms of expression), while 'drawing' includes transformations on the perceived and probabilities beyond expectations. The cognitive approach here considers the cognitive process as an extension of the designer's mind in drawing.

When drawing is considered as a way of thinking, it is evaluated through cognitive processes. In cognitive neuroscience research, Vinod Goel treats the mind as a computer, arguing that the mind needs a tool to represent information and make calculations. In other words, the cognitive process requires a representative tool. He describes it as 'the language of thought'. Goel (1995) analysed the symbolic nature of representation with 'Sketches of Thought'. Through the perspective of Goel, the concept of sketching refers to the non-notational symbol system. The sketch is an uncertain, fluid, amorphous, and unstable graphic expression. Goel explains thinking as symbol manipulation; the drawing allows continuous manipulation of symbols, but somehow it becomes a cognitive activity.

All of these studies on drawing have investigated different cognitive approaches and cognitive activities in the design process. Studies acknowledge that the cognitive process is not only in the mind of the individual but also in the relationship he/she has with the design tools used. The cognitive process, however, does not define a gap that is wholly externalised or between internal and external. On the contrary, this approach assimilates the coexistence of internal and external resources. Unlike traditional theories, this approach, Distributed Cognition, extends cognition beyond the individual to include interactions with people, and the resources and materials around them. He argues that cognition is dispersed among people, artefacts, and tools in the environment, rather than just being the head of individuals (Hollan et al., 2000).

Distributed cognition can be distinguished from other approaches by its adherence to two relevant theoretical principles: (1) the boundaries of the unit of analysis. In opposition to the traditional views, distributed cognition is not limited to individuals but also to the elements involved outside of the individuals. It tries to find a system that can dynamically configure itself to coordinate subsystems that perform various functions; (2) the extent to which it can 
be assumed to be involved in cognitive processes (Hollan et al., 2000). Traditional views seek cognitive events in the manipulation of symbols within individual actors, whereas distributed cognition seeks a broader class of cognitive events. In this approach, the physical thinking environment provides additional memory by expanding processes running only in internal memories.

James Hollan, Edwin Hutchins, and David Kirsh (2000) argue that since the human mind creates internal models of the external world, it cannot be seen as passive representative engines. There is a complicated relationship between the internal resources that express memory, attention, and execution and the external resources that express artefacts and objects that continuously surround the body. Distributed cognition takes the human body and the material world into focus and explains the cognitive process developed through the interactions between internal and external resources. With this approach, the tools used by individuals become a part of their cognition. Similar to a blind person's cane being the central part of his/her perception of the world, the pen for a designer integrates into the individual's way of thinking, seeing, and controlling as part of his/her distributed cognitive system.

\section{Case Study}

The formation of memory can be defined as a product of a complex cognitive process. The tools we use, our bodies, and our actions are the parts of this process. In this sense, we can assume that the boundaries of the cognitive process go beyond the brain and are distributed between the inner images that the mind stores and processes along with the outer representations that are the outcome of our actions and relations with the materials. The case study focuses on how a particular space is experienced, and how the experience constitutes the memory when drawing. It investigates the transfer of mental memory to an external memory with an active cognitive process by drawing.

\section{Content and the Key Concepts of the Study}

French philosopher Henri Bergson (1939) defines everything around us, including our bodies, as images, and defines memory through the relationship with these images. For Bergson, memory transcends consciousness, as it cannot be fully activated in its presence. Numerous memories that we never remember are powerless and ineffective. However, although we are not aware of them, unconscious memories affect our behaviour and shape our subjective experiences. Based on his model, he divided the memory into two types. Accordingly, the first one is habitual memory, which is gained through physical tendencies and motor skills. In perception, we act on habitual memory because we are concerned with objects for their benefits and actions (Bergson 1939). Second is the virtual memory, which consists of the recollection of these images and is defined as reflection.

Similar to Bergson's model of memory, its formation through drawing changes based on how the cognitive process forms. The spontaneous first experience and the recalling of that experience are differently defined. This differentiation is also reflected in the stages of the study. In this way, the study consists of repeating different drawing, including two stages, which are the transfer of first-hand experience and the recollection from memory. These two stages are repeated through the exercise. First, drawing is visualised as the direct experience of a visual notetaking. It is a process in which the participant gains his/her first input about the space. The first experiment is converted to an external representation by using the representation symbol system. It includes the spatial organisation of the building and the arrangements of the unique features that creates a perceptual reference; whereas the second phase of the study is based on recalling the experiences of the drawing activity that takes place in the first phase. The type of the drawing task remains the same; however, the participant is asked to draw what he/she remembers about the space by looking or experiencing it physically.

\section{Method of the Drawing Activity}

The drawing activity was planned as a series of protocols for searching the formation of the memory through drawing. In the literature, the studies on drawing focused on the cognitive process that is based on the observation of the drawing process. These studies were either applied as protocol studies that simulate a design process or taken place in an initial design process in a studio environment. They were mainly applied through empirical observation of the drawing experience. With a similar approach, this study focuses on the act of drawing and the drawn material about its mental references. The study has two different sources of data collection. The first one is the simultaneous observation during the drawing activity. In this process, the researcher did not take an active role in the drawing activity but became a passive observer of the process. The second source is the material itself providing a retrospective look at the action. This includes interviews with the participants of the drawing activity. From a phenomenological approach, the evaluation is done based on the experiential findings of the subject. The narrative of the participant includes the expressions of how the perception of space is formed and what is remembered.

The study was carried out in a specific location with a defined protocol. For this drawing activity, a compact observation group was determined that consisted of five people. The participants were chosen from graduates that have an architectural background in order to have a conventional knowledge of an architectural representation. 
In other words, they were expected to have the ability to read and draw sections, plans, and elevations. The drawing activity is an "on-site" study. The site selected was a place that the participants had not experienced before, thereby, the goal of observing how memory is created by drawing from the first experience can be achieved. The selected place for this activity was an old local village house that was transformed into a cafe in the countryside. The building has a basic plan organisation as a single mass. In addition to the cafe usage, the place serves as a florist and contains many different and vibrant visual elements that stimulate perception. Unlike the structural mass, the space is full of decorative features that shape the spatial organisation.

In the application of the drawing activity, participants were asked to represent their spatial experiences through drawing. They were free to draw sections, elevations, and the plans of the place that are the most proper way to show the outline of the mass, the interior circulation, and the proportional relations. Drawings were made in sketch format in which accuracy was not a criterion, instead, they were produced based on observation and experience of the body. According to the defined protocol, the process was limited to 15 minutes for each drawing to express the instant reflection of the memory.

\section{Application of the Study}

Through these drawing studies, there is an identical differentiation between the two phases in terms of the drawing methods and what is drawn. The first phase of the study is the translation of the initial experience (Figs. $1,3,5)$. Even though perception is supposed as holistic, it consists of the sum of the fragmented pieces. This was reflected in the drawing as eclectic and indecisive lines. Each line on the paper indicates the decision of what space is. Even though it was roughly defined, the drawn elements were established with individual scale relationships. For those relations, some of the objects were taken as reference scales. The drawing took 12 to 15 minutes to develop a complete experience. It was observed that the focus of the drawing was to represent the interior of the building by noting the information about the massing of the space and features included in.

The second phase presents a pattern, like a selfconversation, of the participant (Figs. 2, 4, 6). As Schön's discussion, the drawing and the drawer's interaction form a cognitive process. Each materialised form on the paper becomes a reference for the following actions of drawing. In this phase, the drawing reveals a distributed mental process to re-experience the space as the only source of the information in mind. At this time, the participant used multiple lines to form the drawing. Lines moved from lighter to darker, indecisive to decisive. During the drawing phase, while the surrounding relations were

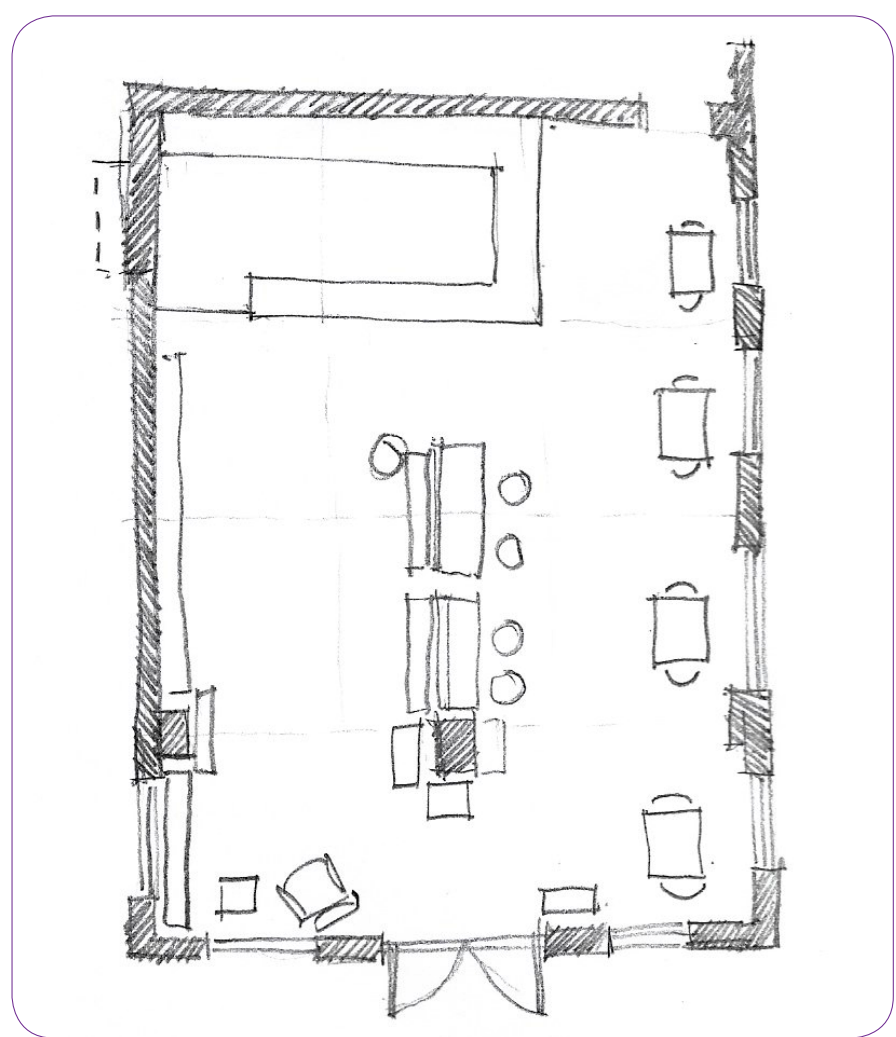

Figure 1. Stage 1 Plan Drawing.

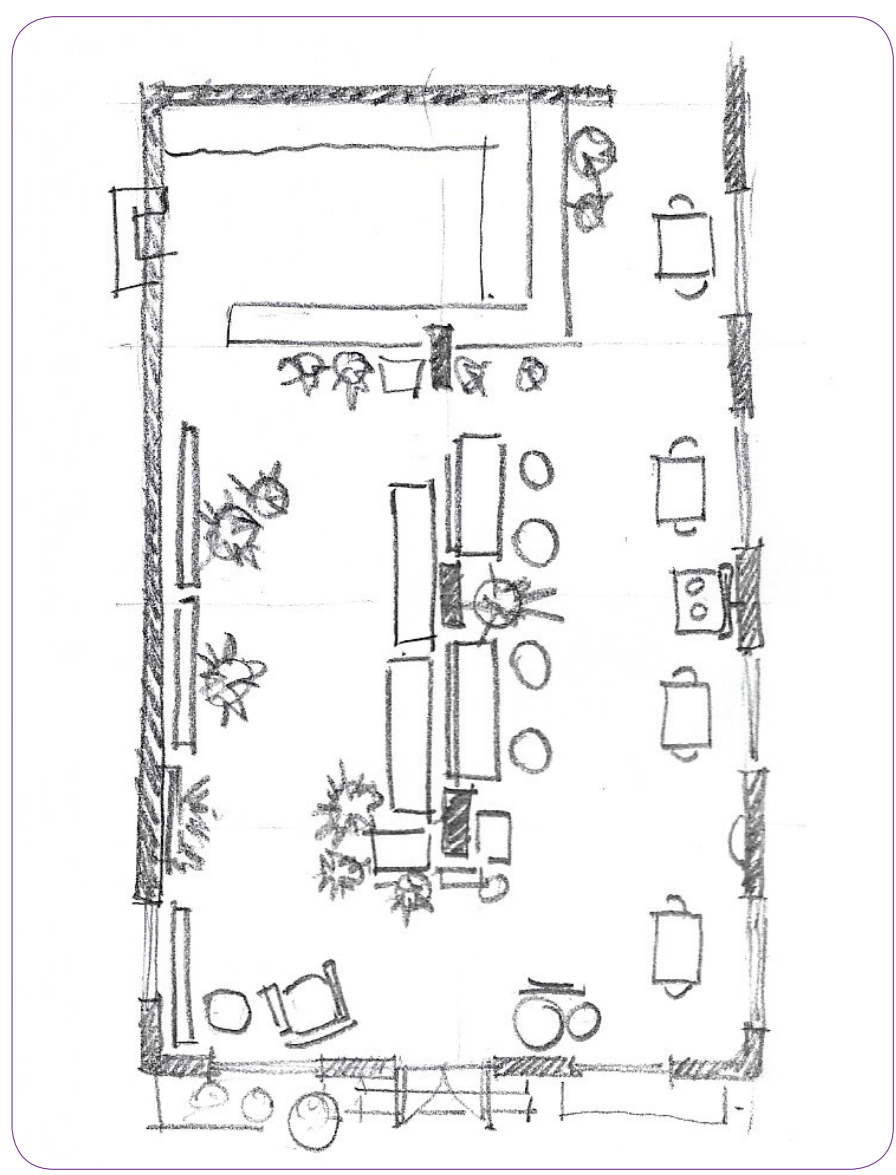

Figure 2. Stage 2 Plan Drawing. 


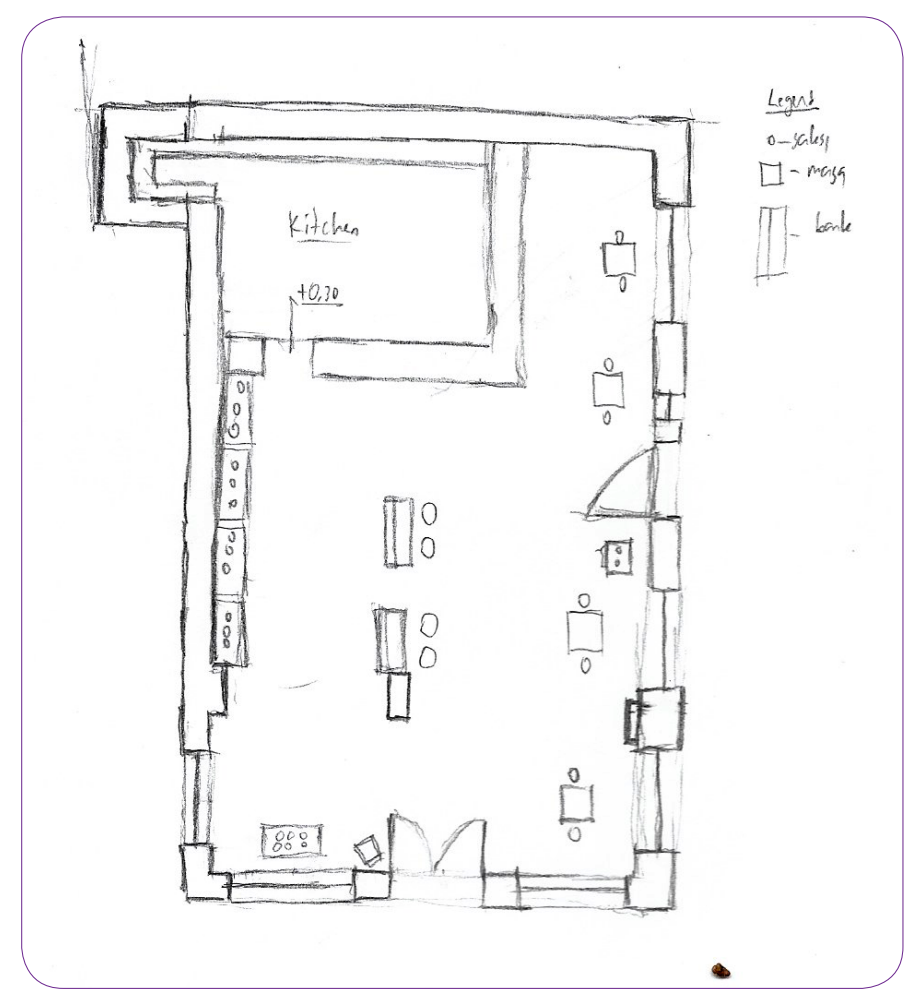

Figure 3. Stage 1 Plan Drawing.

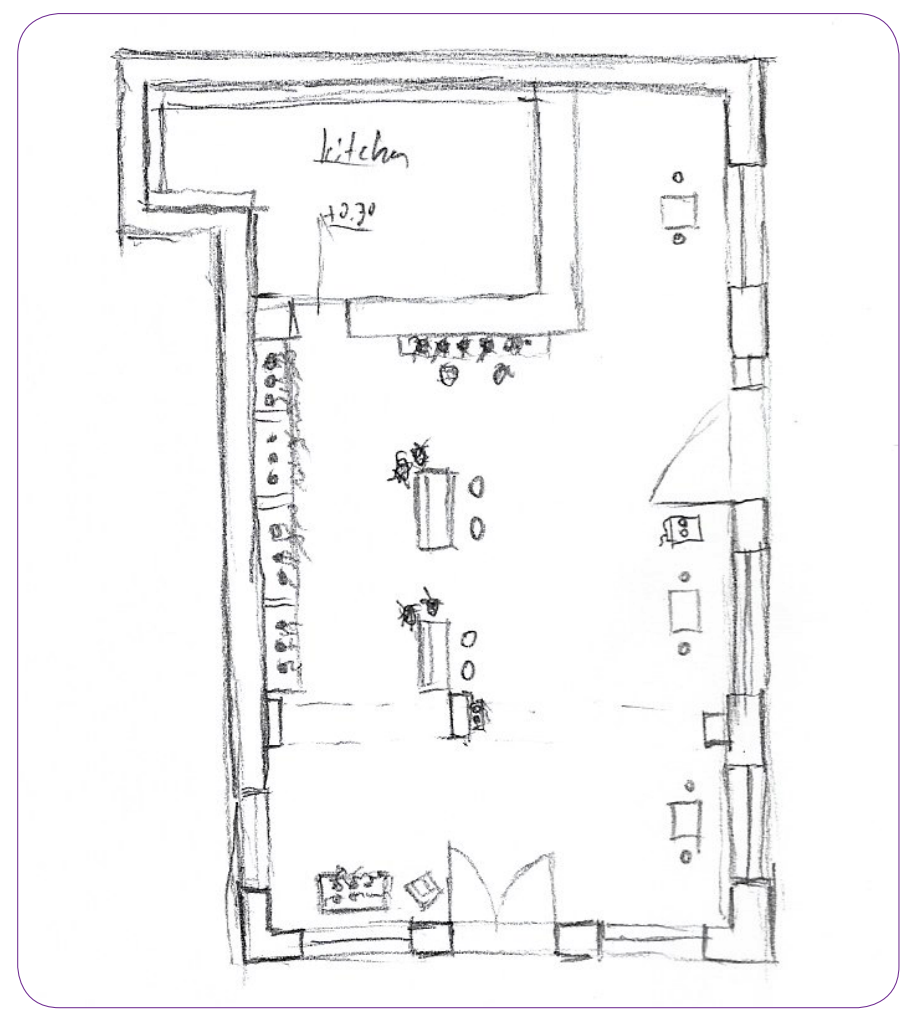

Figure 4. Stage 2 Plan Drawing.

drawn, the place where the participant sits and draws were illustrated correctly, whereas the other parts were not matching with the real conditions of the space. This demonstrates the body and its interaction with space.

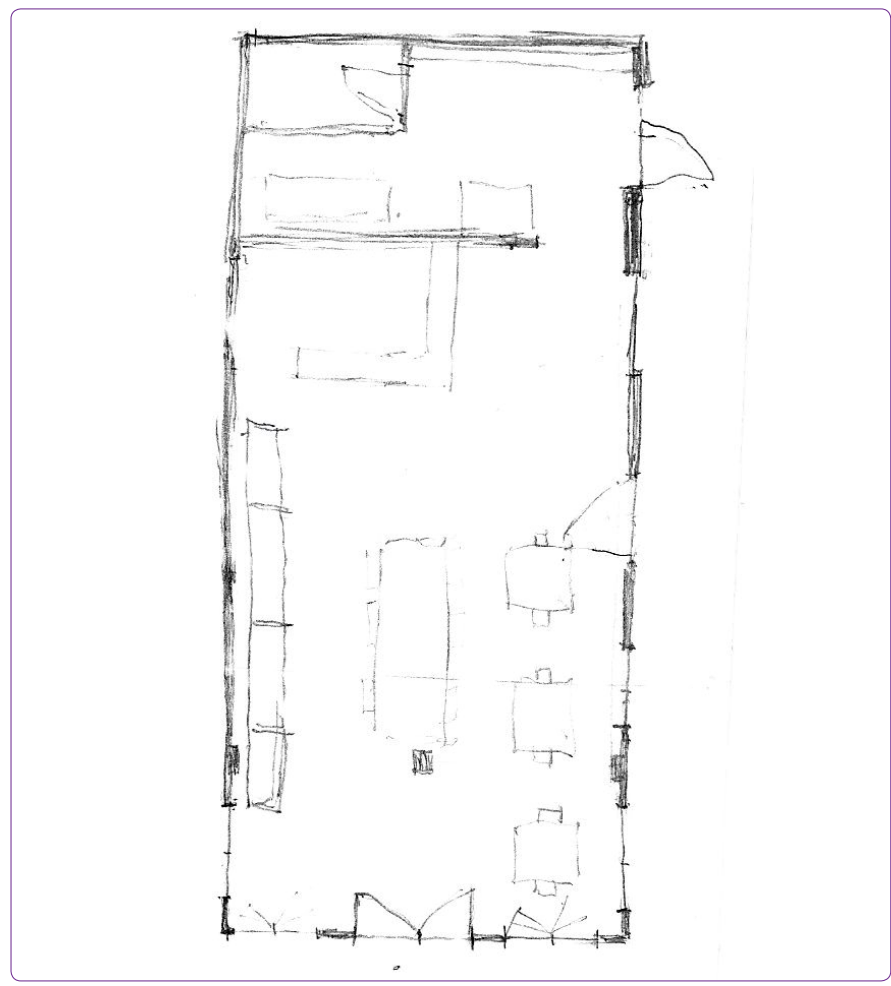

Figure 5. Stage 1 Plan Drawing.

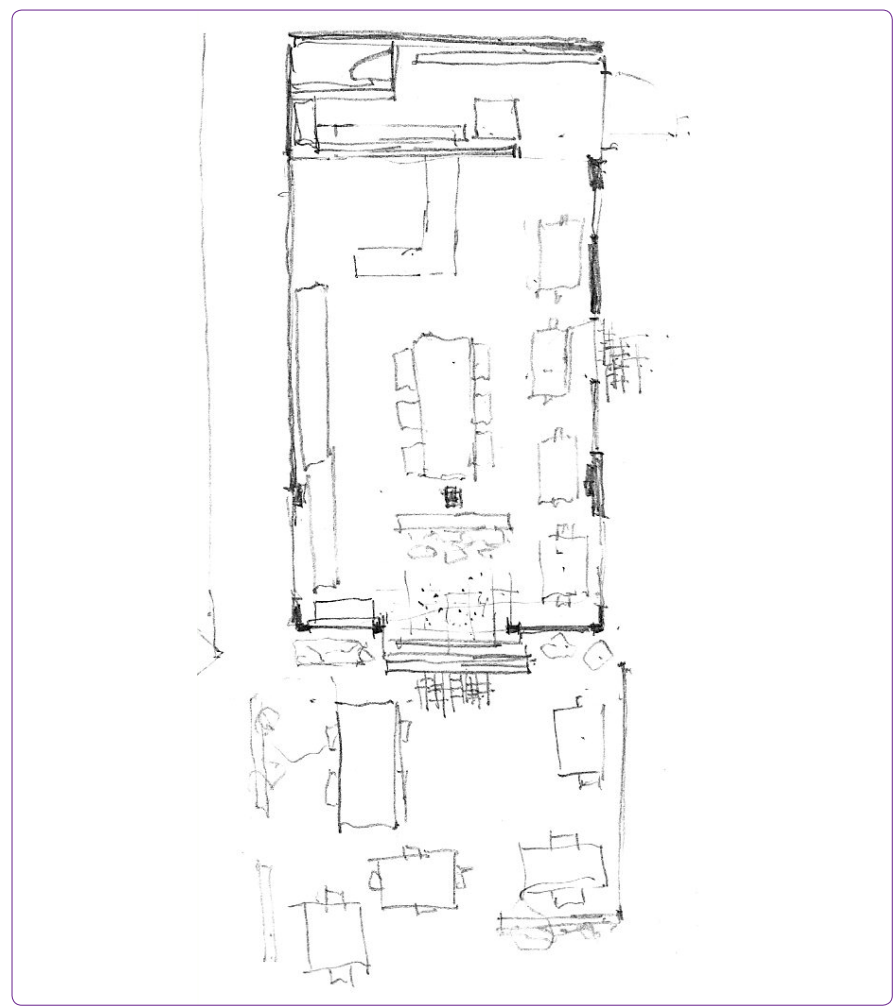

Figure 6. Stage 2 Plan Drawing.

Similarly, it is observed that the parts that were not experienced nor seen were represented larger than they were or left empty. Later, it was noticed that, when the view being observed was blocked or too dense to identify 
each element separately, the observer perceived that view as a single loaded image.

Compared to the first phase, the second phase was completed in a shorter time. This phase of drawing was very detailed, including the furniture and decorative elements. To complete the features of the drawing, the participant shared the steps by giving feedback as a selfconversation. By recalling the experience, the participant was able to draw the opening direction of the closet door by repeating the movement and stimulating the mind. However, the same door was not drawn correctly in the first phase of the drawing because it was not drawn during the note-taking process, but completed later hypothetically without thinking. In this phase, the information on the drawing was based on personal perception. The entanglement of mind in space creates different realities of experience. For instance, in reality, the entrance stairs were higher than the standard dimensions and create difficulty to climb, whereas the participant represents them as standard dimensions but horizontally very wide. When the sections were compared, similar to the plan drawings, it was observed that the horizontal and vertical dimensions of the first drawing were compatible with the space itself, whereas the second drawing showed differences according to the participant's personal experiences (Figs. 7-10).

The perception of the space has been based on form. In both of the drawing stages, the form of the space was defined in the drawing eclectically or as a whole. During

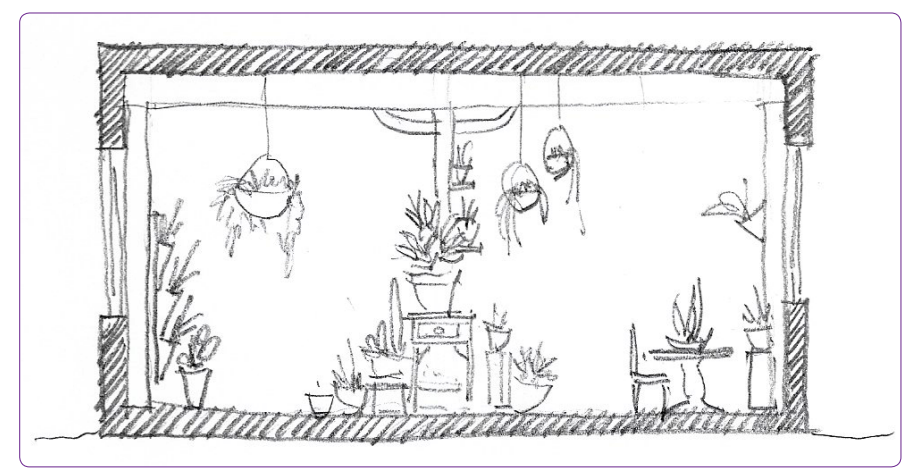

Figure 7. Stage 1 Section Drawing.

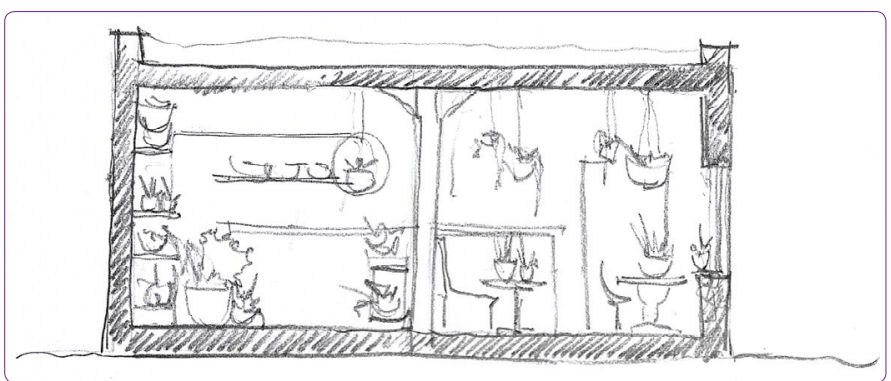

Figure 8. Stage 2 Section Drawing.

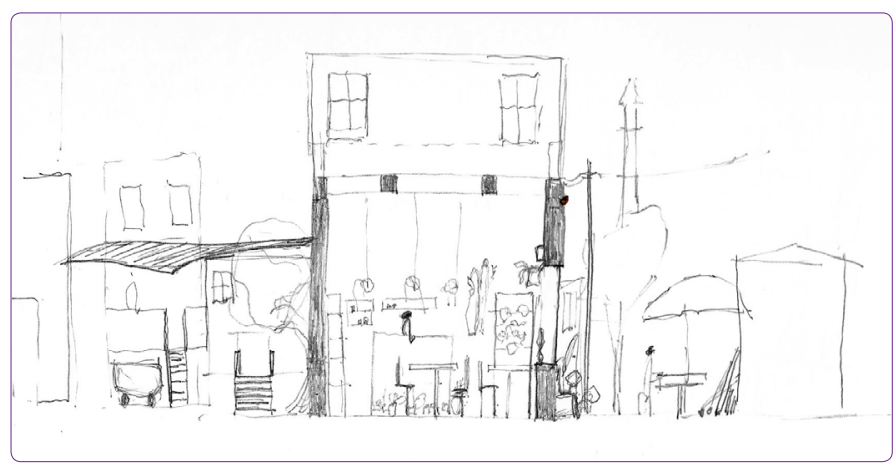

Figure 9. Stage 1 Section Drawing.

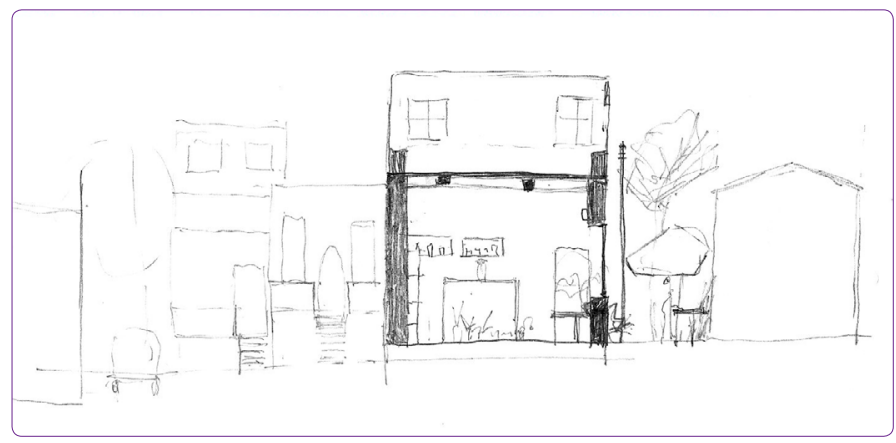

Figure 10. Stage 2 Section Drawing.

the drawing process, it was observed that the initial act was defining the formal expression of the structure and the positions of the furniture. This process was followed by the illustration of the complementary elements of the space, which are, in this case, the stacks of pots, plants of various sizes, and decorative elements. Although there were differences in details while analysing the drawings, the form was developed over perceived voids. This illustrates that our perception of space is not formed by the mass but is constituted by the void that is experienced through the movement of the body.

\section{Evaluation of the Study}

Considering the cognitive approaches, memory is not a medium of passive data storage, but has stages of data processes in terms of retention, reactivation, and reconstruction of the experience. Experience gained from the environment is followed by the variety of memory processing, which is presented here in the case study as direct retention, a note-taking process, and the recall of the experience. Based on the phenomenological analysis, how the experience is expressed on the drawing surface has been evaluated.

Bearing in mind the evolution of the expressed phenomenon on the paper, the processing of the drawn memory is being formed by the obtained data. Even though the protocol defines different data sources for each stage of the drawing activity, in both stages the cognitive process was developed by the relationships 
established both from the internal and external memory traces. When the two created situations were compared, the missing information reflected on the drawing surface in the first stage was completed by using active experience and architectural knowledge of the participant (Fig. 12). However, the source of the data is the mental memory; in other words, the recall experience in which the mind fills the missing information from the learned data or completed to a reasonable form by reconstructing the experience (Figs. 11-13). This process is not only a re-enactment of previous experience but also includes complementing the learned information and implementing unconscious data to the whole. This can be expressed as, if there is no data stored in that situation, the mind filling the missing information through assumptions or trying to build up "logical" solutions to illustrate the completing the whole if there are any missing pieces like the Gestalt theory.

In both stages of the drawing activity, the act of drawing constitutes a reflective conversation between the internal representations that is the mental memory, and

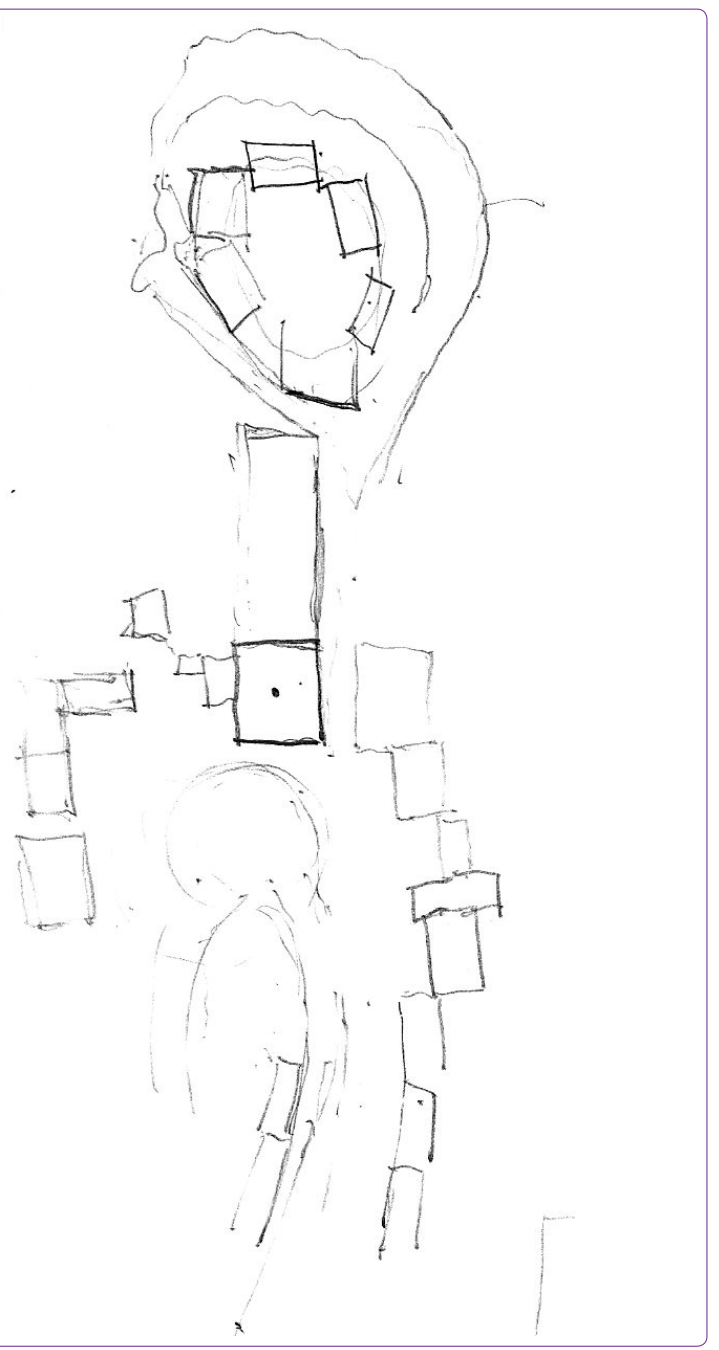

Figure 11. Stage 2 Sketch of the Site Map.

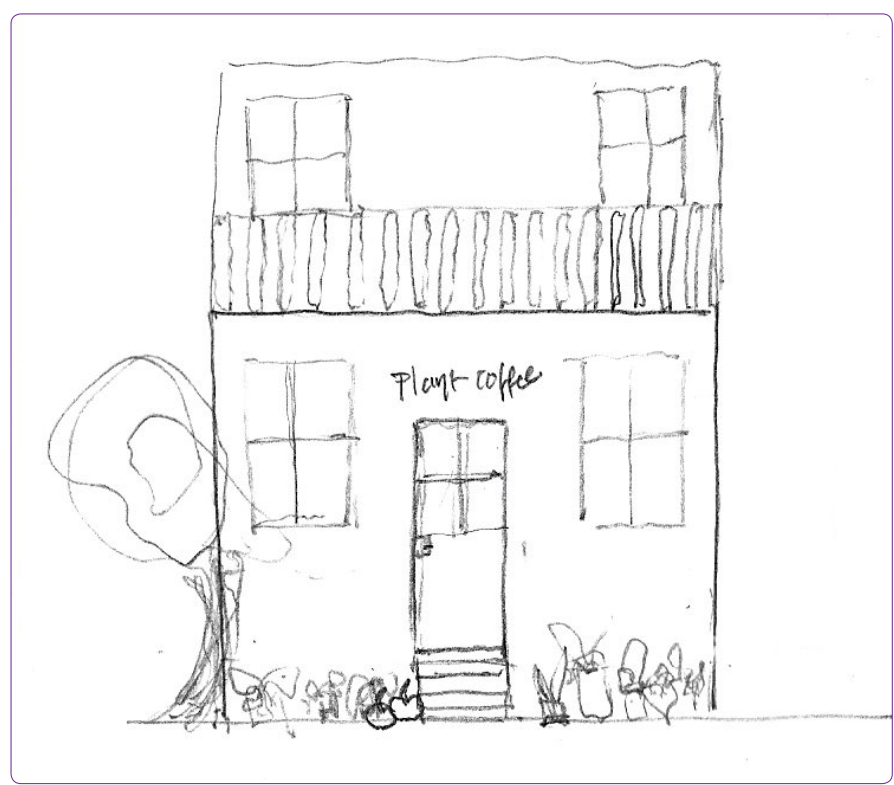

Figure 12. Stage 2 Elevation Drawing.

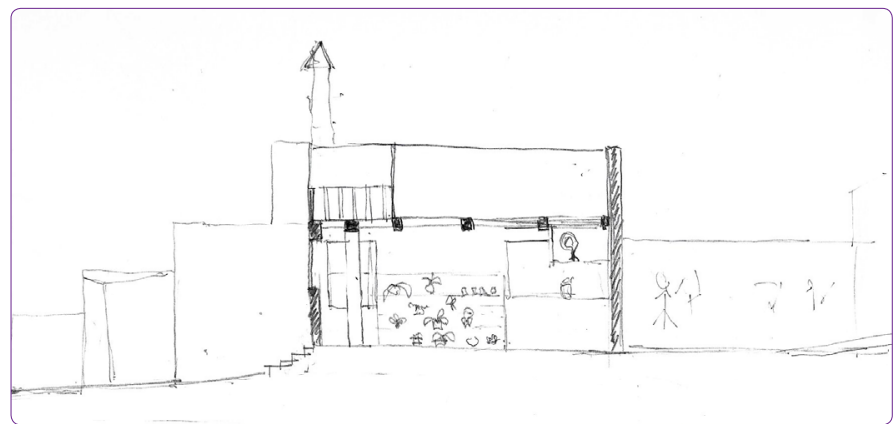

Figure 13. Stage 2 Section Drawing.

the external representations that is the drawing itself, as Schön puts forward. In this context, drawing experience is reactivated by 'doing', which also means the reference of the activity is the relationship between these phenomena of mind and material.

\section{Conclusion}

Drawing for the simple purpose of taking notes or visualizing what we have in mind, often reveals the cognition of the relationship between mind and material. Cognitive studies in the field of design studies agree that the cognitive process is not limited to the mind. What is drawn throughout the drawing becomes the constructive components of the drawing process as a physical extension of mental activity. The formation of perception extends to experience as well as how experience is translated. The formation of perception creates an external memory with "draw" or, in other words, the action of drawing and the drawn. With the drawing, the revealed external memory is not only produced by the experience of the drawer. It is a product of both the internalised experience, which 
is the recalled data from the memory, but also of active cognition by engaging the drawing itself.

\section{References}

Bergson, H. (1939) Matter and Memory. Translated by N.M. Paul \& W.S. Palmer (2012) NewYork, Dover Publications, INC.

Brew, A., Fava, M., Kantrowitz, A. (2012) “Drawing Connections: New Directions in Drawing and Cognition Research", Tracey Journal: Drawing Knowledge, https://Drawing_Connections_ new_directions_in_drawing_and_cognition__research (Last reviewed: December 2019).

Goel, V. (1995) Sketches of Thought. Cambridge, MA: MIT Press.

Goldschmidt, G.L. (1994) "On Visual Design Thinking: The Vis Kinds of Architecture", Design Studies, 15(2), 158-174.

Goldschmidt, G.L. (1991) “The Dialectics of Sketching”, Creativity
Research Journal, 4(2), 123-143.

Hollan, J., Hutchins, E. \& Kirsh, D. (2000) “Distributed Cognition: Toward a New Foundation for Human-Computer Interaction Research", ACM Transactions on Computer-Human Interaction, 7(2), 174-196.

Kantrowitz, A., Fava, M., Brew, A. (2017) “Drawing Together Research and Pedagogy", Art Education, 70(3), 50-60.

Schön, D.A. \& Wiggins, G. (1992) "Kinds of Seeing and Their Function in Designing", Design Studies, 13, 135-156.

Suwa, M. \& Tversky, B. (1997) "What do Architects and Students Perceive in their Design Sketches? A Protocol Analysis", Design Studies, 18(4), 385-403.

Tversky, B. (2002) What do Sketches Say about Thinking? AAAI https://www.tc.columbia.edu/faculty/bt2158/faculty-profile/files/2002_Tversky_Whatdosketchessayaboutthinking. PDF (Last reviewed: December 2019). 